\title{
PENGARUH PERMAINAN MODIFIKASI VOLKRAW DAN PERMAINAN KELOMPOK PASSING TONG TERHADAP HASIL BELAJAR PASSING BAWAH BOLA VOLI DI SMP N 6 PETARUKAN
}

\author{
Islah Tri Kartiko
}

Fakultas pendidikan ilmu pengetahuan sosial dan olahraga, Universitas PGRI Semarang Email: kartikodarto@gmail.com

\begin{tabular}{l}
\hline Artikel Info \\
\hline Koresponden penulis : Islah Tri Kartiko \\
Email: kartikodarto@gmail.com \\
$\square$ Diterima 26 November 2021 \\
$\square$ Direview 11 Juli 2021 \\
$\square$ Disetujui 16 Juli 2021 \\
$\square$ Dipublikasi 17 Juli 2021
\end{tabular}

Kata Kunci: Permainan modifikasi volkraw, Permainan kelompok passing tong, Bola Voli

Keywords: Volkraw modification game, Barrel passing group game, Volleyball

\begin{abstract}
Abstrak
Penelitian dilatarbelakangi karena pembelajaran penjas bola voli saat melakukan pemanasan bersifat monoton halnya guru penjas saat mengajar, menjadikan sebuah pembelajaran kurang efektif. Rumusan penelitian ini bagaimanakah pengaruh permainan modifikasi volkraw dan permainan kelompok passing tong terhadap hasil belajar passing bawah bola voli di SMP $N 6$ Petarukan? Tujuan penelitian ini untuk mengetahui pengaruh permainan modifikasi volkraw dan permainan kelompok passing tong terhadap hasil belajar passing bawah bola voli. Desain penelitian True Eksperimental Design tipe randomized control group Pretest-Posttest. Instrumen tes teori Brumbach forearms wall-volley test. Populasinya kelas VIII di SMP N 6 Petarukan menggunakan random sampling 60 siswa di SMP N 6 Petarukan. Hasil Uji $t$ permainan modifikasi volkraw pretest diperoleh 4,463 permainan modifikasi volkraw postest 4,490. Hasil Uji $t$ permainan kelompok passing tong pretest 2,391 permainan kelompok passing tong postest diperoleh 2,326. Maka pada permainan modifikasi volkraw pretest 4,463 sedangkan permainan kelompok passing tong pretest 2,391 maka 4,463>2,391. Pada permainan modifikasi volkraw postest 4,490 sedangkan permainan kelompok passing tong postest 2,326 maka 4,490>2,326. Disimpulkan bahwa permainan modifikasi volkraw lebih baik dari permainan kelompok passing tong, dari nilai yang di peroleh Uji $t$ nilai permainan modifikasi volkraw menggunakan metode pretest dan postest lebih tinggi nilai permainan modifikasi volkraw.
\end{abstract}

\begin{abstract}
The research is based on the background because learning volleyball when warming up is monotonous as physical education teachers teach, making learning less effective. The formulation of this research is how the effect of the volkraw modification game and the barrel passing group game on the learning outcomes of volleyball under-passing at SMP N 6 Petarukan? The purpose of this study was to determine the effect of the volkraw modification game and the barrel passing group game on the learning outcomes of volleyball underpass. Research design True Experimental Design type pretestposttest randomized control group. The Brumbach forearms wall-volley test theory test instrument. The population was class VIII at SMP N 6 Petarukan using random sampling of 60 students at SMP N 6 Petarukan. The results of the $t$ test of the pretest volkraw modification game obtained 4,463 postest volkraw modification games 4,490. The results of the t-test for the pretest passing group of 2,391 games for the post-test barrel passing group were 2,326. So in the pretest volkraw modification game 4,463 while the pretest passing group play was 2,391 then 4,463> 2,391. In the posttest volkraw modification game is 4,490 while the posttest passing group game is 2,326 then 4,490> 2,326. It can be concluded that the volkraw modification game is better than the tong passing group game, from the value obtained by the t-test, the value of the volkraw modification game using the pretest and postest method is higher than the value of the volkraw modification game.
\end{abstract}




\section{PENDAhuluan}

Berdasarkan

pengamatan

dan

kenyataan di lapangan masih banyak terdapat siswa di SMP N 6 Petarukan belum mampu melakukan passing bawah selama waktu 1 menit dengan baik dan benar hanya ada 10 anak yang melakukan sesuai dengan target dari 30 siswa yang diharapkan. Sebagai seorang guru olahraga atau pelatih bola voli dituntut untuk dapat memberikan cara atau metode pembelajaran suatu teknik dasar passing bawah dan atas bola voli secara benar, sebab cara pembelajaran yang tepat akan memudahkan siswa untuk menguasai teknik dengan baik, dan dapat menimbulkan rasa percaya diri juga dapat meningkatkan semangat siswa untuk belajar.

Melihat pernyataan diatas, maka satu pemikiran yang muncul adalah bahwa perlu adanya suatu pembelajaran di SMP N 6 Petarukan yang mampu menciptakan kegembiraan dan kesenangan serta mengajak siswa aktif dan antusias dalam pembelajaran, yaitu perlu adanya modifikasi dalam permainan yang diterapkan oleh seorang guru. Cara ini salah satu usaha untuk mengarahkan dan membelajarkan siswa agar lebih mudah memahami materi dan terciptanya suasana dalam pembelajaran itu sendiri menjadi senang, gembira dan dengan sendirinya siswa akan antusias dan aktif dalam proses pembelajaran tersebut, yang tadinya tidak bisa menjadi bisa, dari tingkat yang tadinya rendah menjadi memiliki tingkat yang lebih. Ini dikarenakan terciptanya suasana yang diinginkan oleh siswa.

Berdasarkan pendapat latar belakang diatas, Penelitian ini dilatar belakangi karena di dalam pembelajaran penjas mata pelajaran bola voli saat melakukan pemanasan bersifat monoton seperti halnya guru-guru penjas saat mengajar, yang menjadikan sebuah pembelajaran menjadi kurang efektif. Rumusan dalam penelitian ini adalah bagaimanakah pengaruh permainan modifikasi volkraw dan permainan kelompok passing tong terhadap hasil belajar passing bawah bola voli di SMP N 6 Petarukan. Pada dasarnya tujuan yang hendak dicapai dalam penelitian ini adalah untuk mengetahui pengaruh permainan modifikasi volkraw dan permainan kelompok passing tong terhadap hasil belajar passing bawah bola voli di SMP N 6 Petarukan. permainan dapat disimpulkan sebagai kegiatan yang sangat menyenangkan terutama bagi setiap orang, karena dengan bermain setiap orang atau anak merasa senang dan dapat meluapkan untuk mendapatkan kepuasaan batin. Juga dapat membantu peneliti dalam menyelesaikan permasalah dengan menggunakan metode permainan.

\section{KAJIAN}

Menurut Arma Aboellah (dalam Guntur, 2009:15) menyatakan pendidikan jasmani merupakan bagian integral dari pendidikan secara keseluruhan melalui kegiatan jasmani yang bertujuan 


\begin{tabular}{|c|c|}
\hline & Journal STAND: Sports and Development \\
http://jurnal.unipasby.ac.id/index.php/stand/about/submissions \\
unipa Suralm,
\end{tabular}

mengemangkan individu secara organik, neuro muscular, intelektual dan emosional.

Permainan bola voli merupakan salah satu keterampilan memainkan bola dengan kerja sama tim yang solid yang terdiri dari 2 group masing-masing group terdiri dari 6 pemain, permainan akan berakhir bila salah satu regu mencapai skor 25 dan regu tersebut sebagai pemenangnya. Permainan ini dilakukan 2 kali (2 set) atau 3 kali apabila satu tim tidak dapat mencapai skor 25 dalam 2 kali berturut-turut. (Husni,A. Dkk. 2014)

Sutristomi dan Sudarso, (2014: 570) "Modifikasi pembelajaran dapat dikaitkan dengan kondisi lingkungan pembelajarannya. Modifikasi lingkungan ini dapat diklasifikasikan ke dalam beberapa klasifikasi seperti modifikasi peralatan. Dalam hal modifikasi yang perlu diperhatikan adalah dengan peralatan yang dapat dikurangi atau ditambah tingkat kompleksitas dan kesulitan tugas ajar sehingga pembelajaran akan dapat berlangsung dengan baik dan motivasi belajar siswa jadi meningkat.

Sutikno (2014:49) menyebut salah satunya dengan nama „metode kerja kelompok $^{\text {ee }}$. Metode kerja kelompok ini akhirnya didefinisikan Sutikno sebagai upaya dari dua orang atau lebih yang saling membantu untuk melaksanakan tugas atau mengerjakan program yang bersifat prospektif untuk mewujudkan kesejahteraan bersama.

\section{METODE PENELITIAN}

Metode penelitian yang digunakan dalam penelitian ini adalah penelitian eksperimen dengan pendekatan diskriptif kuantitatif. Eksperimen adalah suatu penelitian yang dilakukan secara ketat untuk mengetahui hubungan sebab akibat diantara variabel-variabelnya. Salah satu ciri pokok dari penelitian eksperimen adalah adanya perlakuan (treatment) yang diberikan ke subjek penelitian (Maksum, 2012: 13).

Desain yang digunakan dalam penelitian ini adalah desain model True Eksperimental Design tipe randomized control group Pretest-Posttest Design dengan mengingat adanya kelompok kontrol, ada perlakuan, subjek ditempatkan secara acak, dan adanya pretest-posttest untuk memastikan efektifitas perlakuan yang diberikan, pemilihan sampel kemudian diberi pretest untuk mengetahui keadaan awal adalah perbedaan antara kelompok eksperimen dan kelompok kontrol. Populasi menurut (sugiyono 2009 : 37) tidak lain adalah wilayah generalisasi yang terdiri atas objek atau subjek yang mempunyai karakteristik tertentu yang ditetapkan oleh peneliti untuk dipelajari dan kemudian ditarik kesimpulannya. Jadi, populasi pada prinsipnya adalah semua anggota kelompok manusia, binatang, peristiwa, atau benda yang tinggal bersama dalam satu tempat dan secara terencana menjadi target kesimpulan dari akhir suatu penelitian. Pada penelitian 
ini yang menjadi populasi adalah siswa kelas VIII SMP N 6 Petarukan yang berjumlah 300 siswa

Adapun sampel yang digunakan dalam penelitian ini adalah $20 \%$ dari populasi sebanyak 300 siswa kelas VIII SMP N 6 Petarukan tahun ajaran 2020-2021 yang representatif. Sampel yang dibutuhkan sejumlah 60 siswa yang diambil dengan teknik random sampling cara undian dari jumlah siswa kelas VIII.

Teknik sampling yang digunakan dalam penelitian ini adalah random sampling, karena populasi berkait dengan fokus yang diteliti menunjukkan sifat homogen. Di samping itu sampling ini pengambilan subjek dari setiap strata atau wilayah ditentukan seimbang atau sebanding dengan banyaknya subjek dan masing-masing strata atau wilayahTeknik sampling yang digunakan dalam penelitian ini adalah random sampling, karena populasi berkait dengan fokus yang diteliti menunjukkan sifat homogen. Di samping itu sampling ini pengambilan subjek dari setiap strata atau wilayah ditentukan seimbang atau sebanding dengan banyaknya subjek dan masing-masing strata atau wilayah.

Menurut Suharsimi Arikunto (2009 :3) eksperimen yaitu suatu cara mencari hubungan sebab-akibat antara dua factor yang sengaja ditimbulkan oleh peneliti dengan mengurangi atau menyisihkan factor-faktor yang lain yang bisa menganggu. Eksperimen selalu dilakukan dengan maksud untuk melihat akibat dari suatu perlakuan Tes yang dipakai dalam penelitian ini adalah test kecakapan pass bawah dalam permainan bola voli. Teori Brumbach forearms wall-volley test (Borreik dalam M.Yunus, 2006:201). Tujuan alat tes ini adalah untuk mengukur kemampuan/kecakapan passing bawah dalam permainan bola voli.

Metode penelitian menjelaskan rancangan kegiatan, ruang lingkup atau objek, bahan dan alat utama, tempat, teknik pengumpulan data, definisi operasional variable penelitian, dan teknik analisis.

\section{HASIL DAN PEMBAHASAN}

Penelitian ini dilakukan untuk mengetahui pengaruh permainan modifikasi dan permainan kelompok terhadap hasil belajar passing bawah bola voli SMP N 6 Petarukan dilaksanakan selama 4 minggu dimulai bulan Agustus. Peneletian ini dilakukan 4 kali pertemuan dengan alokasi waktu 3 X 40 menit untuk kelas yang menjadi subjek penelitian. Subjek dalam penelitian ini adalah siswa kelas VIII A dan VIII B dengan 1 kelas kontrol yaitu VIII C subjek penelitian menggunakan 2 kelas dengan jumlah siswa 60 siswa.

Normalitas data digunakan untuk menguji apakah dalam model regresi, variabel independen dan variabel dependen keduanya terdistribusikan secara normal atau tidak. Uji Normalitas data dalam penelitian ini menggunakan one sampel Kolmogorov- 
smirnov Test. Hasil pengujiannya adalah sebagai berikut:

Tabel 4.6

Hasil perhitungan Uji t

\begin{tabular}{lcccc}
\hline & \multicolumn{4}{c}{$\begin{array}{c}\text { Std.Err } \\
\text { or }\end{array}$} \\
\hline 1 (Constant) & $-52,035$ & 17,096 & 4,04 &, 00 \\
& & & & \\
& 1,411 &, 314 & 4,49 &, 00 \\
Permainan_Modifikasi & & & 0 & 0 \\
_posttest & & & 2,32 &, 02 \\
$\begin{array}{l}\text { Permainan_Kelompok_Po } \\
\text { sttest }\end{array}$ & 1,363 &, 586 & 6 & 8 \\
\hline
\end{tabular}

Sumber: Data Primer yang diolah, 2020

Uji t bertujuan untuk menguji pengaruh satu variabel penjelas/independen secara individual dalam menerangkan variasi variabel dependen, dengan tingkat signifikansi 0,05 .

Pengaruh antara Permainan

Modifikasi volkraw (X1) Permainan

Kelompok passing tong (X2) terhadap Hasil

Belajar (Y). Berdasarkan hasil pengujian hipotesis permainan modifikasi volkraw dan permainan kelompok passing tong yang menggunakan metode pretest dan postest terhadap hasil belajar di SMP Negeri 6 Petarukan. Ditunjukkan dengan hasil uji $\mathrm{t}$ yang menunjukkan permainan modifikasi volkraw menggunakan metode pretest diperoleh nilai 4,463 sedangkan permainan modifikasi volkraw menggunakan metode postest diperoleh nilai 4,490. Selain itu berdasarkan hasil uji t yang menunjukkan permainan kelompok passing tong menggunakan metode pretest diperoleh nilai 2,391 sedangkan permainan kelompok passing tong menggunakan metode postest diperoleh nilai 2,326. Maka pada permainan modifikasi volkraw menggunakan metode pretest 4,463 sedangkan permainan kelompok passing tong menggunakan metode pretest 2,391 maka 4,463>2,391 selain itu pada permainan modifikasi volkraw menggunakan metode postest 4,490 sedangkan permaianan kelompok passing tong menggunakan metode postest 2,326 maka 4,490>2,326. Dengan demikian dapat disimpulkan bahwa permainan modifikasi volkraw lebih baik dibandingkan permainan kelompok passing tong, hal ini dapat dilihat dari nilai yang di peroleh pada uji t yang menunjukkan nilai permainan modifikasi volkraw menggunakan metode pretest dan postest lebih tinggi dari pada nilai permainan kelompok passing tong.

\section{KESIMPULAN}

Dari hasil analisis, maka kesimpulan yang dapat diambil adalah sebagai berikut :

1. Hasil analisis menunjukan bahwa permainan modifikasi volkraw berpengaruh signifikan terhadap hasil belajar.

2. Hasil analisis menunjukan bahwa permainan kelompok passing tong berpengaruh signifikan terhadap hasil belajar.

3. Hasil analisis semua variabel bebas membuktikan bahwa permainan modifikasi volkraw dan permainan kelompok passing tong berpengaruh terhadap hasil belajar.

Volume 2 Nomor 1 Tahun 2021 | 30 


\begin{tabular}{|c|c|c|}
\hline Unipa Suralaga & $\begin{array}{l}\text { Journal STAND: Sports and Development } \\
\text { http://jurnal.unipasby.ac.id/index.php/stand/about/submissions } \\
\text { jurnal.stand@unipasby.ac.id }\end{array}$ & 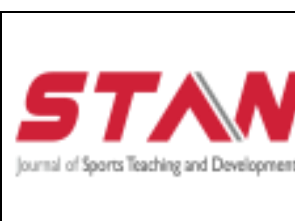 \\
\hline
\end{tabular}

4. Hasil pengaruh menunjukkan bahwa permainan modifikasi volkraw yang menggunakan metode pretest dan postest lebih baik dari pada permainan kelompok passing tong yang menggunakan metode pretest dan postest.

5. Hasil dari penelitian tersebut menunjukkan signifikan terhadap hasil belajar, semua variabel sama-sama berpengaruh dan menggunakan metode pretest- postest . Dalam hasil peneletian yang lebih baik adalah permainan modifikasi (vokraw).

\section{REFERENSI}

Ariyanto, E. 2013.” Upaya Meningkatkan Minat, Motivasi dan Hasil Belajar Lompat
Jauh Gaya Hang Style dengan Media Bola Gantung bagi Siswa Kelas VIII A SMP N 1 Randublatung Kabupaten Blora Tahun 2012/2013". Skripsi. Semarang: Fakultas Ilmu Keolahragaan Universitas Negeri Semarang. Diterbitkan 2013.

Badan Standar Nasional Pendidikan. 2007."panduan penilaian kelompok mata pelajaran pendidikan jasmani olahraga dan kesehatan. Jakarta: BNSP.

Cahyanto, A.G.I \& Hidayat, T. 2015."pengaruh modifikasi permainan terhadap hasil belajar passing atas bola voli (studi pada siswa kelas VII C SMP N 1 Tulangan Kabupaten Sidoarjo)." Jurnal Jurnal Pendidikan Olahraga dan Kesehatan Volume 03 Nomor 03 Tahun 2015, $691-695$.

Erianti. (2010). Buku ajar bola voli. Padang: Sukabina Offset. 